\title{
O USO DE CALORIMETRIA EM ECOLOGIA
}

\author{
Claudio Airoldi \\ Instituto de Química - Universidade Estadual de Campinas - CP 6154 - 13083-970 - Campinas - SP
}

Recebido em 2/7/97; aceito em 9/2/98

\begin{abstract}
THE USE OF CALORIMETRY IN ECOLOGY. The macroscopic effects caused by sun radiation and the mankind-nature interactions in a ecosystem are firstly presented. However, the importance of calorimetric determinations to clarify some phenomena related to the living microorganism populations and their interactions with the food additive or inhibitor agents are reported. The collect values illustrate the occurence a great deal of effects in this microscopic world. For this subject, the reachest Latosol soil was selected due to the content of organic matter and consequently in microorganisms. Microbial activity was stimulated by addition of glucose, which showed to be the best nutrient source. Inhibitory effect was detected with many compounds used in the agriculture like some herbicides and fungicides. Although the assays are based on the use of the microcalorimetry, other techniques like respirometry contributes strongly to the understanding of the ecosystem. The main objective in this exposition is to stimulate by means of many interesting examples, the importance of preserving the environment in order to establish direct analogies by using the Chemistry in the daily life.
\end{abstract}

Keywords: microorganisms; inhibitor agent; ecosystem; microcalorimetry, food additive.

\section{INTRODUÇÃO}

Nos dias de hoje, é inegável o marcante teor de benefícios que provém das atividades relacionadas à Química em nossa sociedade, muito embora sérios dissabores possam ser acarretados pelo uso indevido de produtos químicos. Na maioria das vezes, esses efeitos são causados por profissionais pouco habilitados, ou mesmo, por aqueles que desconhecem a potencialidade da ação deste ramo da ciência.

$\mathrm{O}$ descarte em rios e lagos, o lançamento na atmosfera e o uso indiscriminado de produtos químicos no solo são atividades que merecem um controle adequado, principalmente numa sociedade que exige a cada momento, maior atenção das autoridades para prevenção do meio ambiente ${ }^{1}$, o que aumenta a importância do papel do químico, devido ao conhecimento sobre os vários efeitos causadores de danos.

Dos aspectos enumerados acima, vamos nos ater mais diretamente ao último, uma vez que o largo uso, principalmente de defensivos agrícolas, faz com que ocorra um acúmulo no solo, afetando o ambiente ${ }^{2}$. Os vários produtos químicos usados afetam o desenvolvimento de microrganismos, já que esses são na realidade os agentes responsáveis pela degradação de vários substratos, cujo estágio final produz nutrientes altamente enriquecedores da fertilidade do solo $^{3}$.

O controle do uso de compostos químicos no solo pode ser acompanhado por várias técnicas, mas, o presente enfoque será direcionado às medidas calorimétricas. Em especial, a microcalorimetria desempenha um papel fundamental na aquisição de dados relacionados aos vários aspectos ambientais. Assim, potencialmente os ecossistemas formados por solo ou água, plantas e animais, por fauna ou flora especiais, de vida e particularmente àquela relacionada à vida microbiológica em diferentes temperaturas, com ingredientes distintos e suprimento de oxigênio ou em diferentes gradientes geográficos ou elevação podem ser efetivamente estudados através desta técnica ${ }^{4}$. O objetivo desta publicação consiste em apresentar alguns dados que possam elucidar o entendimento do uso de compostos químicos num ecossistema, dando sempre que possível, uma abordagem quantitativa aos fenômenos observáveis.

\section{UMA PANORÂMICA ENERGÉTICA NUM ECOSSISTEMA}

A obtenção de dados quantitativos confiáveis exige, inicialmente, que se estabeleça um sistema bem definido. Nele delimita-se um ambiente no qual o nível das populações e dos grupos das espécies que pertencem ao ecossistema, as quais têm um relacionamento direto com a biosfera, o que caracteriza a ecologia, sendo que esta trata da ciência do habitat. Neste ambiente se encontram condições de vida dos seres e as interações de quaisquer naturezas entre seres vivos e seu meio ${ }^{5,6}$.

No âmbito macroscópico, o sistema em apreço contém uma paisagem agradável, com clima temperado e constituída de florestas, rios, lagos e montanhas, que recebem diretamente radiações solares. A incidência dos raios provoca o aparecimento de fenômenos de características macroscópicas observáveis e de fácil compreensão. Casos mais simples envolvem a evaporação da água dos leitos e a fusão do gelo, que foi depositado no período invernal no topo da montanha. Para cada mol do líquido ou sólido $(18,02 \mathrm{~g})$ nas condições padrões $(1 \mathrm{~atm}=101,325 \mathrm{kPa}$ a $298,15 \mathrm{~K}$ ), o ambiente é resfriado pelo consumo de energia nos processos endotérmicos ${ }^{7}$, como representados abaixo:

$$
\begin{aligned}
& \mathrm{H}_{2} \mathrm{O}(\mathrm{l})=\mathrm{H}_{2} \mathrm{O}(\mathrm{g}) ; \Delta_{\mathrm{v}} \mathrm{H}_{\mathrm{m}}=44,01 \mathrm{~kJ} \mathrm{~mol}^{-1} \\
& \mathrm{H}_{2} \mathrm{O}(\mathrm{s})=\mathrm{H}_{2} \mathrm{O}(\mathrm{l}) ; \Delta_{\text {fus }} \mathrm{H}_{\mathrm{m}}=6,01 \mathrm{~kJ} \mathrm{~mol}^{-1}
\end{aligned}
$$

Nesse ecossistema o fluxo do efeito térmico dos raios solares e a distribuição da água contribuem para a parte cultivável do solo. A produção diária do efeito térmico sobre o solo varia de 300 a $710 \mathrm{~kJ} \mathrm{~m}^{-2}$. A evaporação da água em camadas ${ }^{8}$ entre 0,42 a $0,98 \mathrm{~mm}$ do solo, implica no acréscimo de um fluxo diário de cerca de $1000-2400 \mathrm{~kJ} \mathrm{~m}^{-2}$.

A biomassa real deste sistema complexo pode ser conhecida através do processo de combustão completa. A partir do teor obtido em micro escala pode-se inferir o efeito produzido pela destruição de toda uma floresta, que como se sabe, os gases expelidos na atmosfera afetam os aspectos climáticos do ecossistema. Porém, por esta mesma técnica pode-se também 
determinar a energia produzida pela matéria orgânica originada nos processos metabólicos. Por exemplo, a combustão completa da celulose produzida pelas plantas dá uma entalpia exotérmica de $-5,86 \mathrm{~kJ} \mathrm{~g}^{-1}$, cujo valor é muito semelhante àquele da glicose $\mathrm{e}^{9}$.

A energética de nutrição dos alimentos retirados pelos seres racionais ou irracionais do ecossistema pode ser simulado em laboratório, através da combustão. Neste caso, necessita-se de uma etapa posterior para que se possam comparar os resultados obtidos in vitro com aqueles dos animais. Após a subtração dos compostos insolúveis e indigestos, os resultados dão uma visão mais realística, porém, não tão precisa ${ }^{6}$. Os críticos ressaltam que os animais ensaiados não são bombas calorimétricas ${ }^{10}$, já que este dispositivo é acoplado a um calorímetro, para que se obtenha o teor energético do alimento selecionado. No entanto, foram avaliados os efeitos térmicos gerados por microrganismos em queijos ${ }^{6}$ e frutas em processo de decomposição ${ }^{11}$, bem como a relação entre a atividade microbiana com o conteúdo de água no alimento ${ }^{12}$.

A mobilidade inevitável do homem no ecossistema afeta de maneira drástica o meio ambiente. Basta considerar que um automotor consumindo um mol de etanol $\left(46,07 \mathrm{~g}\right.$ ou $\left.58,4 \mathrm{~cm}^{3}\right)$ produz, em combustão completa, dióxido de carbono e água gasosa, num processo altamente exotérmico ${ }^{7}$, cuja energia resultante da reação é utilizada para mover o auto, conforme mostra a reação:

$\mathrm{C}_{2} \mathrm{H}_{5} \mathrm{OH}(\mathrm{l})+3 \mathrm{O}_{2}(\mathrm{~g})=2 \mathrm{CO}_{2}(\mathrm{~g})+3 \mathrm{H}_{2} \mathrm{O}(\mathrm{g}) ; \Delta_{\mathrm{c}} \mathrm{H}_{\mathrm{m}}=-1235 \mathrm{~kJ} \mathrm{~mol}^{-1}$

Os produtos gasosos desta reação lançados na atmosfera do ecossistema alteram o equilíbrio existente. Mesmo não entrando no mérito da controvertida discussão do efeito estufa, no qual a molécula de dióxido de carbono é tida como uma das substâncias com ativa participação. Este efeito está relacionado ao recebimento da radiação solar pelo ecossistema, cuja radiação é composta predominantemente de pequenos comprimentos de onda, nas regiões do visível e ultravioleta com 98 e $2 \%$, respectivamente. Parte desta radiação ao atingir a superfície é reirradiada para o espaço em comprimentos de onda maiores, na região do infravermelho, e passa a ser absorvida por moléculas, que reirradiam em todas as direções. Neste processo a superfície do ecossistema perde menos calor para o espaço e tende a permanecer mais quente ${ }^{13}$, o que implica em readaptação de todos os seres frente à nova situação.

A vida vegetal no ecossistema está associada à presença da luz, água e energia solar, no conhecido processo da fotossíntese, que provoca a extraordinária reação redox, convertendo o dióxido de carbono e água em carboidrato e oxigênio ${ }^{14}$. Este fenômeno é dependente dos pigmentos verdes das plantas em cuja composição está a clorofila. Como se sabe, a raiz da planta absorve a água através dos vasos para levá-la até as folhas onde penetra nos cloroplastos. Dentro dos mesmos as clorofilas possibilitam a quebra da molécula de água devido à radiação solar, para liberar oxigênio. Este é utilizado em parte pela planta e todos os outros seres no processo da respiração. Por outro lado, a molécula de gás carbônico, aparentemente inerte, disponível no ambiente, entra nos cloroplastos, que em presença de certas enzimas se ligam ao hidrogênio, para produzir moléculas complexas, como celulose e açúcares. Estas são transferidas dos cloroplastos para as outras partes da planta para dar inclusive, sustentação à mesma.

A dinâmica provocada pela tríade luz, água e energia contribui para a sobrevivência e interações dos seres vivos no meio ambiente. Neste particular, a participação de seres vivos macroscópicos é extremamente importante, pois, em princípio, são eles os agentes dominantes sobre a superfície. Após esta visualização de alguns aspectos energéticos macroscópicos, o enfoque agora será dirigido à população de seres de dimensões microscópicas, que habitam o subsolo e que são extremamente sensíveis à presença de substâncias químicas no meio ambiente.

\section{MONITORAMENTO DE EXPERIMENTOS}

O fluxo de efeito térmico no ecossistema pode ser monitorado pelo consumo de oxigênio, pela produção de dióxido de carbono, ou pelo acompanhamento de algum substrato, contendo elementos nuclearmente marcados. Esta última técnica, além de bastante dispendiosa, exige condições experimentais adequadas ${ }^{15}$.

O acompanhamento da produção de dióxido de carbono pode ser seguido através da denominada calorimetria indireta. A calorimetria direta embora seja um método não específico que detecta qualquer efeito térmico envolvido, é a única maneira de quantificar o metabolismo aeróbio e não aeróbio em um sistema ${ }^{15,16}$. A calorimetria é fundamental para o conhecimento do sistema e tem características técnicas vantajosas, pelo fato de que a medida em si independe das condições de opacidade do ambiente, o que a difere da maioria das técnicas espectrofotométricas. Além do mais, é não destrutiva e permite obter medidas por longo período ${ }^{6,15-18}$. Dai, as mudanças entálpicas verificadas num ecossistema são fundamentalmente obtidas via calorimetria. Estes dados podem ser associadas ao processo respiratório por acompanhamento da evolução de dióxido de carbono ${ }^{6,15-18}$.

Do ponto de vista termodinâmico as populações de organismos contidas num sistema aberto podem trocar matéria, energia e informações com a vizinhança. Todas estas atividades produzem um fluxo de efeito térmico, que provém de processos metabólicos relacionados com reações do meio e acarretam em mudança de entalpia. Desta maneira, no processo metabólico uma série reações se completa ou atinge um estágio estacionário após longo período, e portanto, devido a estas características, o processo de estudo do avanço lento da reação requer, mais especificamente, o uso da microcalorimetria ${ }^{6,15-23}$.

A calorimetria direta oferece as melhores condições para a obtenção global do fluxo térmico, muito embora as influências tóxicas e não-específicas possam dificultar as medidas. Por isso o assunto é relativamente pouco explorado ${ }^{6}$. Por outro lado, recomendam-se cuidados especiais para tratar o problema porque os efeitos interativos exigem a manutenção da vizinhança de vivência dos microrganismos, o que implica em considerar sempre a influência do mundo microscópico do ecossistema na medida ${ }^{6}$.

$\mathrm{O}$ equilíbrio dinâmico da vida neste ecossistema é diretamente afetado pela participação do homem, que pode adicionar substâncias químicas, materiais descartáveis ou ainda injetar radiações no solo. Somente os primeiros serão considerados já que são usados com frequência como defensivos em nosso meio, com o intuito de propiciar maior produção agrícola, visando atender um crescente aumento populacional humano. Dentre estes defensivos temos fundamentalmente os herbicidas e os fungicidas, que no solo residem tempos diversos antes de chegar à total decomposição. Durante esta permanência esses produtos afetam a água, o poder de troca e uso de cátions livres do solo pelas plantas e ainda a conversão da possível biomassa existente em combustível ${ }^{6}$.

Um fato relevante que vem ao encontro da obtenção de dados energéticos através da calorimetria está relacionado às falhas detectadas por processos puramente bioquímicos, provenientes dos fluxos de energia, que fluem num ecossistema. Estes dados indicam que até o momento, $60 \%$ do total energético são perfeitamente explicados através de caminhos bioquímicos. A calorimetria permite a obtenção do efeito global, além de abranger todas as questões da área ecológica, físiológica e toxicológica ${ }^{15}$. Por isto mesmo, esta técnica torna-se muito importante no estudo de problemas toxicológicos, provenientes da presença de substâncias químicas no meio ambiente.

\section{O SOLO}

Do ponto de vista químico o solo é um sistema complexo em constituição, aberto, multicomponente e biogeoquímico, 
formando um conglomerado de sólidos, líquidos e gases. Por ser aberto pode trocar matéria e energia com a atmosfera, biosfera e hidrosfera, sofrendo contínuas transformações químicas e biológicas. O fluxo de matéria e energia depende das variáveis tempo e espaço, mas, em geral este fluxo causa o desenvolvimento do perfil do solo e governa a fertilidade ${ }^{24}$.

As regiões geográficas próximas podem apresentar população microbiana variável, dependendo de ser o solo natural sem cultivo, estensivamente usado na agricultura ou contendo sedimentos aquáticos ${ }^{25}$. O teor de matéria orgânica existente no solo correlaciona-se em grande parte com as substâncias húmicas, cuja população microbiana decresce com a profundidade de coleta da amostra ${ }^{4,25}$.

Do ponto de vista pedológico, o latossolo que tem propriedades ácidas, é um solo comum em nosso país, cobrindo um pouco mais da metade do território brasileiro, apresentando-se com características diversas, sendo o roxo o que possui constituição orgânica mais abundante. A diversidade de população é bem marcante, especialmente no solo roxo, que abrange $15 \%$ do estado de São Paulo ${ }^{26}$. Algumas propriedades de solos brasileiros $^{23}$ são comparadas com solos indianos ${ }^{27}$ como na tabela $^{2}$ 1. O teor de matéria orgânica e a capacidade de troca catiônica são mais pronunciadas em nossos solos. Os solos indianos têm características tendendo a $\mathrm{pH}>7$, o que é marcante nos solos do hemisfério norte. As características de $\mathrm{pH}$ do solo brasileiro propiciam a troca iônica, como demonstram os ensaios realizados em processo de batelada, sendo que a saturação é atingida rapidamente. Nesta troca o solo libera prótons ao meio, que originalmente estavam ligados à matriz inorgânica ou aos ácidos húmicos que fazem parte dos componentes orgânicos do solo. Assim, o grau de troca é sempre acompanhado por uma variação de $\mathrm{pH}^{28}$, que está ilustrada em função da concentração de cátions sobrenadantes, como mostra a figura 1. Por outro lado, o conhecimento do $\mathrm{pH}$ do solo propicia condições para o ajuste do meio na efetivação do plantio. Em nosso país o pH é corrigido com adição de calcáreo, enquanto que o oposto ocorre no hemisfério norte, onde são usadas soluções de ácidos. De um modo geral, as amostras compostas de solo são coletadas a uma profundidade de 5 a $10 \mathrm{~cm}$, após a remoção da camada da superfície. As mesmas são peneiradas na granulometria desejada, secas ao ar e acondicionadas em sacos plásticos ${ }^{23}$.

Tabela 1. Algumas propriedades comparativas de solos: $\mathrm{pH}$ (1,0 mol dm $\left.\mathrm{dm}^{-3} \mathrm{Ca}^{2+}\right)$, MO matéria orgânica (\%/g solo) e CTC capacidade de troca catiônica $(\mathrm{mmol} / 100 \mathrm{~g}$ solo) para latossolo roxo (LR), latossolo vermelho escuro (LV), latossolo amarelado (LA), Aligarh-India (AI) e Haldighati-India (HI).

\begin{tabular}{lllr}
\hline Solo & $\mathrm{pH}$ & MO & CTC \\
\hline LR & 5,2 & 3,3 & 6,8 \\
LV & 4,0 & 3,0 & 7,9 \\
LA & 3,5 & 4,6 & 12,2 \\
AI & 9,3 & 0,4 & 5,8 \\
HI & 6,0 & 0,2 & 3,9 \\
\hline
\end{tabular}

\section{ATIVIDADE MICROBIANA NO SOLO}

A atividade microbiana no ecossistema depende da população vivente no meio. Qualquer perturbação causa uma reação, que vem sempre acompanhada da evolução de um efeito térmi$\operatorname{co}^{29}$. Esta reação pode ser estimulada através de adição de uma fonte de carbono degradável. A permanência da celulose por mais de $50 \mathrm{~h}$ no solo não surtiu qualquer efeito térmico, porém, o inverso foi verificado com açúcares. Os dados mostram que a atividade microbiana no solo de aluvião frente a diferentes açúcares apresenta respostas que seguem a ordem: glicose

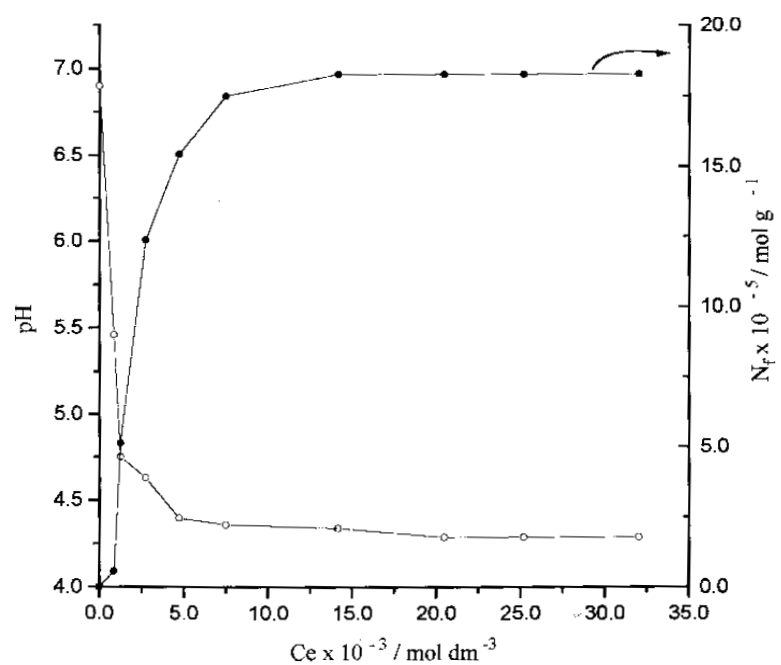

Figura 1. Troca iônica realizada com soluções variáveis de cloreto de cobre em uma suspensão aquosa de 1,0 g de latossolo roxo, mantido sob agitação mecânica a $298 \mathrm{~K}$. Os resultados estão representados através da variação de $\mathrm{pH}(\mathrm{o})$ e número de moles de cobre trocados com prótons do solo $N_{f}(\bullet)$ em função da concentração do cobre sobrenadante no equlíbrio Ce.

$\left(92 \mathrm{~kJ} \mathrm{~mol}^{-1}\right)>$ sacarose $>$ lactose $>$ frutose > galactose > manose $\left(64 \mathrm{~kJ} \mathrm{~mol}^{-1}\right)^{21}$.

A simulação experimental da degradação do açúcar é sempre feita na presença de outro componente, além da manutenção de umidade constante ${ }^{23}$. Vários xenobióticos à base de fosfatos, carbonatos e sulfatos foram testados neste mister, porém, o que apresenta melhor resultado é o sulfato de amônio $^{19,20,23}$. Em condições propícias a degradação ocorre à temperatura constante, através da microcalorimetria, que pode estar associada à respirometria ${ }^{15}$, cujos resultados dependem da temperatura e umidade do meio ${ }^{23,30}$. A figura 2 mostra a degradação de amostras de glicose e sulfato de amônio em $53 \%$ de umidade em duas diferentes temperaturas. Os sinais calorimétricos foram registrados numa curva de potência em função do tempo. Os efeitos térmicos para um dado experimento foram calculados através da integração das áreas das curvas, que foram comparadas com aquelas obtidas por calibração elétrica. Assim, os efeitos térmicos observados para ambas as temperaturas, correspondem às respectivas áreas dos picos, os quais forneceram para a degradação de $6,0 \mathrm{mg}$ de glicose e 6,0 mg de sulfato de amônio, 22,5 e $29,9 \mathrm{~cm}^{2}$ a 298 e $306 \mathrm{~K}$, respectivamente ${ }^{23}$. No acompanhamento de degradação de amostras de solo por respirometria, o valor limite encontrado de $21,1 \mathrm{~J} \mathrm{~cm}^{-3}$ de dióxido de carbono coletado estabelece que existe larga participação de um metabolismo aeróbio ${ }^{31}$. O decréscimo em atividade está ligado ao aumento do processo anaeróbio, que depende em larga extensão do tipo de habitat e

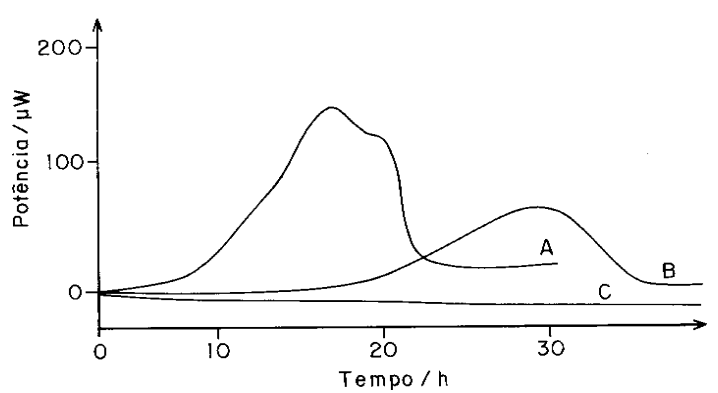

Figura 2. Efeito da temperatura na degradação de 6,0 mg de glicose e $6,0 \mathrm{mg}$ de sulfato de amônio, em umidade 53\%, em latossolo roxo a 306 $K(A), 298 K(B)$. A linha base C representa o solo sem nutrientes. 
da umidade. Para que seja comprovado o efeito da umidade na produção do respectivo efeito térmico, deve-se levar em conta, portanto, amostras de solos de mesma procedência.

Em condições experimentais aérobias duas ampolas idênticas contém em comum, $1,50 \mathrm{~g}$ de solo e mesmo teor de $53 \%$ de umidade. Uma delas atua como branco e a outra como amostra, que receberá adições de nutrientes, podendo ou não estar na presença do inibidor. O sinal resultante é comparado ao branco ${ }^{23}$. Nestas condições a degradação da glicose pode ser escrita como:

$$
\begin{gathered}
\mathrm{C}_{6} \mathrm{H}_{12} \mathrm{O}_{6}(\mathrm{aq})+\underset{2802 \mathrm{~kJ} \mathrm{~mol}^{-1}}{6 \mathrm{O}_{2}}(\mathrm{aq})=6 \mathrm{CO}_{2}(\mathrm{aq})+6 \mathrm{H}_{2} \mathrm{O}(\mathrm{l}) ; \Delta_{\mathrm{r}} \mathrm{H}_{\mathrm{m}}=- \\
2802
\end{gathered}
$$

Esta entalpia da reação em fase condensada foi corrigida para as condições experimentais ${ }^{23}$, resultando $\Delta_{\mathrm{r}} \mathrm{H}_{\mathrm{m}}=-2762 \mathrm{~kJ} \mathrm{~mol}^{-1}$. A quantidade de glicose consumida ( $\left.\mathrm{m}_{\text {cons }}\right)$ devido ao crescimento da população microbiana pode ser calculada pela expressão:

$$
\mathrm{m}_{\mathrm{cons}}=\mathrm{Q}_{\mathrm{obs}}(\mathrm{MM}) / \Delta_{\mathrm{r}} \mathrm{H}
$$

Q molar da glicose $\left(180,16 \mathrm{~g} \mathrm{~mol}^{-1}\right)$. Para uma série de ensaios com quantidades variáveis de nutrientes, os tempos máximos de obtenção dos picos de degradação correlacionam-se com as respectivas entalpias, conforme mostram os dados da tabela 2 . Em todas determinações os cálculos indicam um consumo de glicose de aproximadamente $10 \%$ do total de glicose adicionado ao sistema num período de $50 \mathrm{~h}$. Porém, este percentual muda para 90 no final de $300 \mathrm{~h}^{32}$.

Tabela 2. Resultados da degradação de massas $m$ de glicose e sulfato de amônio (mg) em $53 \%$ de umidade obtidos através das curvas potência versus tempo, indicando para cada pico o máximo de tempo $\mathrm{Tp}(\mathrm{h})$, a área $\mathrm{A}\left(\mathrm{cm}^{2}\right)$, o efeito térmico Q (J) e a massa estimada $\mathrm{m}_{\mathrm{e}}(\mathrm{mg})$ a $298 \mathrm{~K}$.

\begin{tabular}{lcclc}
\hline $\mathrm{m}$ & $\mathrm{Tp}$ & $\mathrm{A}$ & \multicolumn{1}{c}{$-\mathrm{Q}$} & $\mathrm{m}_{\mathrm{e}}$ \\
\hline 3,0 & $29,2 \pm 1,3$ & $11,5 \pm 0,3$ & $3,45 \pm 0,09$ & 0,225 \\
6,0 & $35,2 \pm 1,4$ & $22,5 \pm 0,9$ & $6,75 \pm 0,27$ & 0,440 \\
12,0 & $43,8 \pm 1,8$ & $47,1 \pm 1,9$ & $14,13 \pm 0,57$ & 0,922 \\
\hline
\end{tabular}

A atividade demonstrada por amostras naturais de solo contendo sedimentos aquáticos, que foram coletadas em vizinhanças aeróbias, comprova que os efeitos térmicos dependem da profundidade do sedimento ${ }^{33}$. O fluxo total do efeito térmico é uma indicação da queda da energia química originalmente fixada pela fotossíntese e representa o fluxo de energia bêntica ${ }^{34}$. Estes dados de produção dos efeitos térmicos podem correlacionar com os métodos que se baseiam em outras atividades biológicas, como por exemplo, a concentração de ATP com a atividade de transporte de elétrons no sistema. Por outro lado, a estocagem por longo tempo do sedimento resulta num decréscimo da produção de efeito térmico, devido à exaustão das fontes de alimentação ou variação na composição microbiana do meio ${ }^{35}$.

A alta atividade microbiana em florestas foi determinada sem quaisquer estímulos de aditivos por microcalorimetria, respirometria e concentração de ATP nos horizontes superiores, que mostraram um decréscimo com a profundidade. Da mesma maneira, a umidade de chuva ou de irrigação e adubação estimulam a atividade, enquanto as chuvas ácidas reduzem a bioatividade. Em geral, removendo a limitação de água e misturando as camadas de solo, a atividade microbiana é novamente reconstituída ${ }^{36}$.

Um outro aspecto relacionado ao estudo de solo de floresta consiste em acompanhar simultaneamente os efeitos térmicos e as respectivas perdas de massa de amostras com umidade constante, durante o período de 210 dias. Quando a estas amostras é inoculada uma quantidade calculada de suspensão de microrganismos, os resultados mostram a existência de três fases do metabolismo: a) um aumento do efeito térmico devido ao processo de catabolismo até 42 dias, b) um catabolismo médio de 42 até 120 dias e c) um baixo nível de atividade entre 120 e 210 dias, devido à presença de polímeros recalcitrantes à decomposição. Nestas fases a perda de massa segue paralela ao efeito térmico ${ }^{16}$, como mostra a figura 3 .

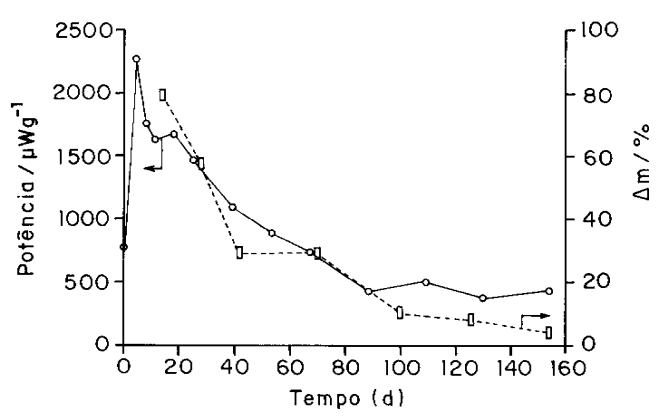

Figura 3. Efeito térmico produzido por microrganismos em solo de floresta (-), comparado com a perda de massa (.....) em função do tempo.

As tendências sazonais afetam os efeitos térmicos no ecossistema. Isto foi comprovado em países com estações climáticas bem definidas, sendo que as curvas calorimétricas variam para um microcosmo marinho ${ }^{6}$. Com amostras de solos brasileiros colhidas em diferentes estações do ano, os resultados apresentaram-se perfeitamente concordantes.

\section{EFEITOS TóxICOS}

Nestes últimos dez anos surgiu uma nova sistemática para detectar poluentes através do uso de bioindicadores. Desta forma, a simples existência de microrganismos no ecossistema facilita o monitoramento das atividades desenvolvidas, quando os mesmos são submetidos a estímulos. Assim, a técnica microcalorimétrica é preferencialmente usada para ensaiar o potencial tóxico de certos xenobióticos. Com este objetivo destacam-se os estudos feitos com metais pesados ${ }^{37,38}$, nitrofenol $^{39}$, pentaclorofenol ${ }^{16,18}$, complexos metálicos do grupo da platina $^{40}$, antibióticos ${ }^{17}$, herbicidas ${ }^{32}$ e fungicidas ${ }^{32}$. Os chamados efeitos tóxicos afetam a fase de crescimento logarítmico das culturas microbiológicas puras, em meio de cultura sintética ou em relação a organismos não-crescentes. Este fenômeno pode ser visualizado na curva de potência em função do tempo, onde o experimento em si é efetuado em meio, onde o solo é o componente que sofre a adição do aditivo e do agente tóxico. Aliás, efeito semelhante foi também observado na produção de populações microbianas em meio de cultura sintético ${ }^{41}$.

$\mathrm{O}$ aumento progressivo da adição de cádmio, mercúrio, ácido selênico e ácido iodoacético ao solo contendo glicose causa um decréscimo da área da curva do registro potência-tempo, o que se reflete num efeito inibidor do crescimento microbiano, em que o máximo da curva exponencial é deslocado para tempos maiores ${ }^{37}$, como está delineado na figura 4 . Os resultados obtidos com compostos de cobre, que são largamente utilizados na proteção de frutas e árvores, mostram um comportamento idêntico aos quatro compostos anteriores ${ }^{42}$. Este fato também foi observado com a adição de certos herbicidas e fungicidas ${ }^{32}$.

O interessante é o modelo cinético ajustado a estes tipos de sistemas, durante o acompanhamento da decomposição da glicose em um meio de cultura ${ }^{37}$. A degradação da glicose em presença do cobre obedece a uma equação de primeira ordem, o que o difere dos demais compostos metálicos ${ }^{42}$. Porém, a 


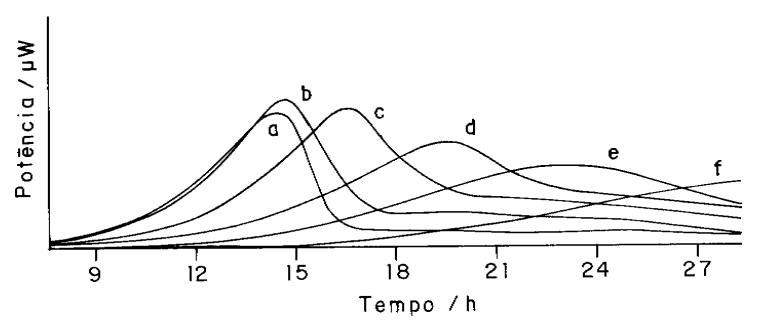

Figura 4. Degradação de $10,0 \mathrm{mg}$ de glicose e $10,0 \mathrm{mg}$ de sulfato de amônio em umidade $25 \%$ em função do tempo a $303 \mathrm{~K}$, tendo: 0 (a), 0,2 (b), 0,4 (c), 0,6 (d), 0,8 (e) e 1,0 (f) $\mu \mathrm{g} / \mathrm{cm}^{3}$ de etilfosfato de mercúrio.

umidade usada foi de 53\%, valor que se afasta dos 20 e $40 \%$ utilizados em outras investigações. Este é um fator importante a ser considerado já que, a umidade afeta drasticamente a forma da curva e conseqüentemente, a entalpia do processo ${ }^{32}$. Uma visualização desta variação entálpica em função do tempo é apresentada na figura 5 , com e sem presença do cobre a $53 \%$ de umidade.

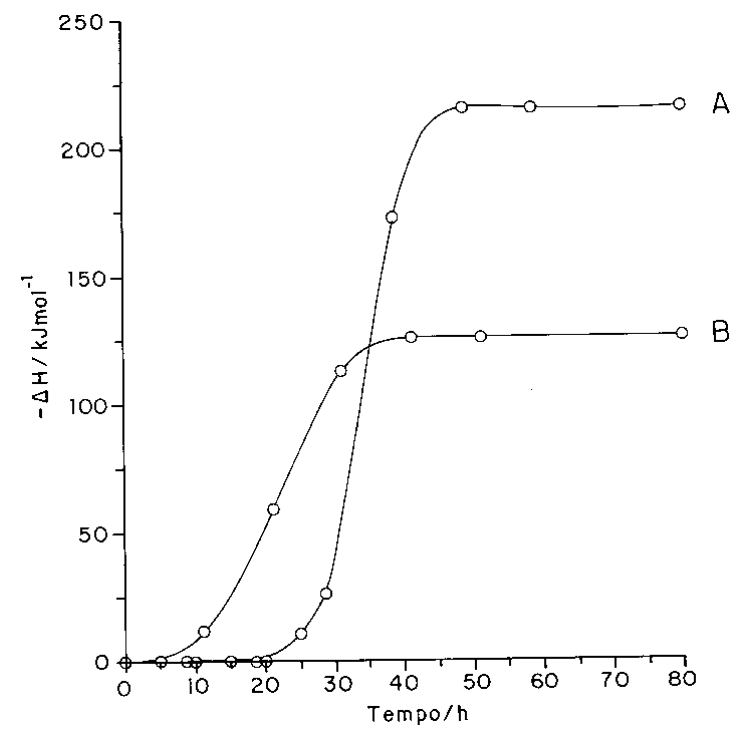

Figura 5. Variação entálpica obtida pela degradação de 6,0 $\mathrm{mg}$ de glicose e $6,0 \mathrm{mg}$ de sulfato de amônio em $53 \%$ de umidade, com latossolo roxo a $298 \mathrm{~K}$. A curva B foi obtida em presença de $2,0 \mathrm{mg}$ de sulfato de cobre e a curva A em ausência do mesmo.

Soluções contendo os herbicidas paraquat (dicloreto de 1,1'dimetil-4,4'-bipiridínio) e diquat (dibrometo de 1,1'-etileno4,4'-bipiridínio) são empregadas em larga escala na agricultura para eliminar ervas daninhas, no conhecido emprego como mata-mato. Quando teores variáveis de herbicidas foram adicionados ao solo contendo glicose com umidade constante, as curvas calorimétricas apresentaram-se com perfis bastante semelhantes ${ }^{32}$. A cinética de degradação da glicose segue bem de perto o comportamento observado com o cobre. Porém, ambos os herbicidas diferem nos valores das variações dos efeitos térmicos na mesma degradação. Por outro lado, as variações dos teores dos herbicidas provocam efeitos térmicos praticamente constantes com a variação da massa dos mesmos. $\mathrm{O}$ fungicida fosfamidon (2-cloro-2-dietilcarboil-1-metilvinila) causa um decréscimo no valor entálpico, que é diretamente proporcional à massa adicionada ao solo ${ }^{32}$.

$\mathrm{O}$ pentaclorofenol (PCP) já foi intensivamente usado como pesticida contra fungos, bactérias, insetos, algas, moluscos, ervas, como desfolhante, além de protetor de madeira, porém, causa ação poluente ao solo ${ }^{15,16}$. Do ponto de vista das atividades biológicas e bioquímicas o PCP tem a capacidade de transferir a energia química do substrato ao ATP, de maneira não acoplada, o que implica na existência de menos ATP formado do que o necessário para manter o organismo em condições metabólicas normais. Consequientemente, consome oxigênio da vizinhança, com o aumento da produção de efeitos térmicos ${ }^{16}$. Este fato foi ilustrado pelo tratamento de solo de floresta em ambiente hermeticamente fechado. Ao ser adicionao o PCP, ocorre imediatamente uma queda do efeito térmico para atingir um patamar. Ao ser aberto o recipiente acontece a aeração. Logo, o efeito térmico volta ao estado inicial e aí permanece por longo tempo, mostrando a dependência do efeito com o oxigênio do ambiente $^{18}$, fato que é ilustrado na figura 6 . Em outras circunstâncias, a adição do PCP acarreta um significante e imediato estímulo ao metabolismo, que cresce sempre em função da concentração, o que até certo ponto contraria os demais comportamentos de aditivos ao solo.

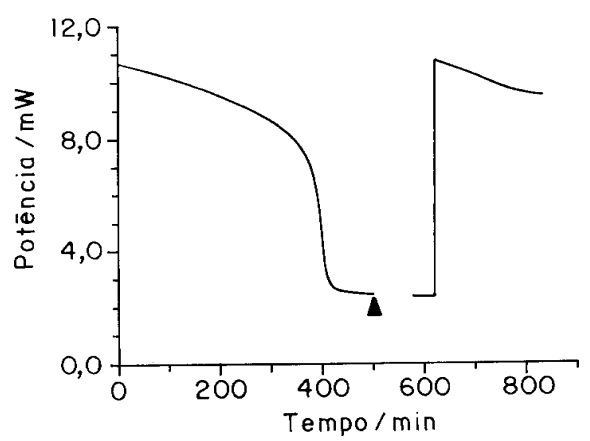

Figura 6. Resultado do efeito térmico produzido pela adição de pentaclorofenol em função do tempo, em um sistema contendo 8,18 $\mathrm{mg}$ do solo fechado em plástico. O triângulo indica o momento de aeração do vaso calorimétrico.

Pequenos animais extraídos do solo do ecossistema também foram submetidos a um banho de solução de PCP em tolueno, sendo a minhoca (Eisenia foetida) um exemplo bastante ilustrativo. Quando embebida nestas soluções de concentrações variando de zero a $60 \mathrm{mg}$ por grama de solo, ocasiona ao animal manifestações, cujos sinais registrados indicam um aumento do efeito térmico em função do tempo ${ }^{18}$. A figura 7 mostra este fenômeno. A linha base ondulada significa a mobilidade do animal no recipiente calorimétrico. Este mecanismo pode ser explicado por provocar fosforilação oxidativa, consumindo energia da célula sem produzir a equivalente energia em forma de ATP, necessária para os processos celulares. O metabolismo aumenta no sentido de retirar energia do organismo, através do consumo de oxigênio e produção de efeitos térmicos crescentes proporcionais à concentração de PCP aplicada. No entanto, concentrações altas produzem um forte metabolismo inibidor ou podem levar o animal a morte ${ }^{18}$.

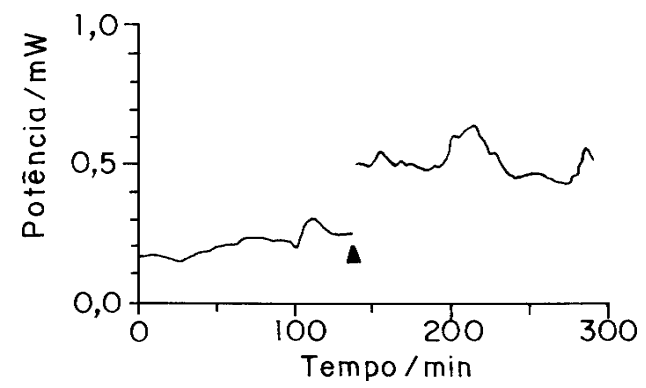

Figura 7. O triângulo limita os efeitos térmicos em função do tempo, obtidos antes e após a minhoca (Eisenia foetida) ser mergulhada em solução de pentaclorofenol em tolueno. 
Os fungos e as bactérias fazem parte da grande composição populacional microbiana existente no solo. Estes microrganismos estão acompanhados de actinomicetos e da própria flora. O número de bactérias em apenas dez gramas de um solo rico foi estimado como sendo igual à população humana no nosso planeta $^{24}$. Contudo, as atividades de bactérias e fungos podem ser distinguidas desde que sejam isolados e aplicados em solos devidamente esterilizados e que contenham um meio de cultura conveniente. Os dados mostram que as bactérias apresentam maior atividade, cujo acompanhamento pode ser facilmente seguido por respirometria ${ }^{32}$. A figura 8 mostra as medidas respirométricas durante o consumo de glicose a $53 \%$ de umidade.

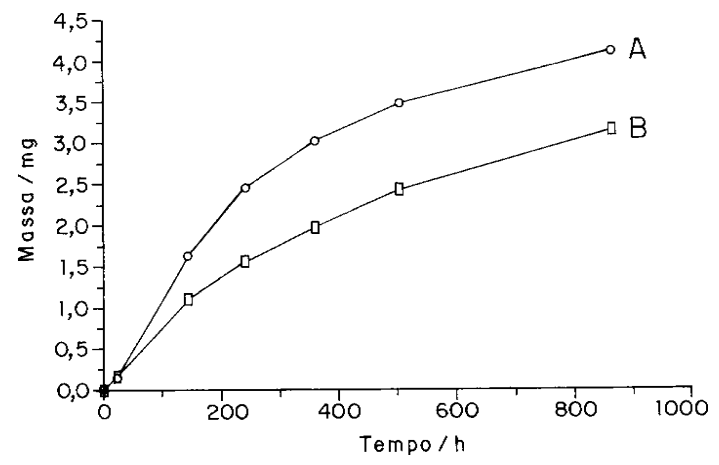

Figura 8. Dados de respitometria de consumo de glicose em amostras de latossolo roxo com $53 \%$ de umidade a $308 \mathrm{~K}$, tendo $6,0 \mathrm{mg}$ de glicose e 6,0 mg de sulfato de amônio (A) e sem nutrientes (B).

Considerando os componentes microbianos, é possível distinguir as atividades individuais através da contribuição do efeito térmico em função de um agente químico conveniente. Assim, a adição de actidiona evidencia somente a atividade de bactérias, enquanto penicilina/estreptomicina permite verificar somente a atividade de fungos. A ação conjunta de ambos os inibidores torna-se útil para saber a total inibição no sistema ${ }^{17}$. Normalmente, para esses tipos de experimentos, a calorimetria pode ser plenamente complementada por ensaios paralelos de microscopia.

\section{CONCLUSÃO}

Nesta apreciação da contribuição da calorimetria ao estudo de um ecossistema, os dados ilustram que esta técnica pode dar marcantes subsídios ao entendimento da ecologia, voltada neste caso, para a atividade microbiológica do sistema. Evidencia-se a substancial vantagem da microcalorimetria por ser rápida e de simples realização quando comparada com tradicionais bioensaios, que exigem um contínuo monitoramento de efeitos. A calorimetria permite o registro de respostas sub-letais e até reações inesperadas. É de rápida resposta com metodologia não específica, para quantificar a variação de entalpia durante o metabolismo, permitindo seguir a cinética da reação e a variação das atividades metabólicas sem que seja necessário monitorar um elemento específico do sistema. Pode ainda ser aplicada com vantagem em sistemas aeróbios, anaeróbios ou mistos.

Os resultados calorimétricos obtidos podem ser associados a outras técnicas para comprovação e, em muitos casos, é bastante desejável, destacando-se neste caso a respirometria. Em todas as determinações a calorimetria dispensa o uso de soluções opticamente claras, o que permite obter dados em suspensões e mesmo em sistemas altamente heterogêneos como são os solos.

A maioria dos dados apresentados trata dos efeitos que certos aditivos causam à ecologia de todo sistema. Neste caso, o homem é altamente responsável, embora em muitas situações sem estar consciente do fato. $\mathrm{O}$ alvo atingido é sempre a população dos microrganismos, que em muitas vezes recebem doses letais.
Os agentes atuantes no ecossistema abrangem a enorme gama de compostos feitos pelo homem, que necessita de esclarecimentos para não comprometer a sociedade. Por outro lado, os exemplos servem para divulgar o expressivo potencial atuante que exercem os xenobióticos na natureza e ainda chamar a atenção para o uso adequado dos mesmos, no sentido de preservar este fantástico mundo microscópico e vastamente rico em população.

\section{AGRADECIMENTOS}

O autor agradece a FAPESP pela renovação do atual sistema calorimétrico e ao $\mathrm{CNPq}$ pela bolsa de pesquisa.

\section{REFERÊNCIAS}

1. Bartell, S. M.; Gardner, R. H.; O’Neil, R. V. Ecological Risk Estimation, Lewis Publishers, London, 1992.

2. Bollag, J. M.; Myers, C. J.; Minard, R. D.; Sci. Total Environ. 1992, 123/124, 205

3. Marsh, K. N.; O'Hare, P. A. G.; Solution Calorimetry, Blackwell, London, 1994.

4. Garett, S. D. Soil Fungi and Soil Fertility, 2nd Edition, Pergamon, Oxford, 1981.

5. Dajoz, R.; Ecologia Geral, Editora Universidade de São Paulo: São Paulo, 1973.

6. Reh, U.; Thermochim. Acta 1991, 193, 107.

7. Atkins, P. W.; Physical Chemistry, Oxford University Press, Oxford, England, 5th Edition, 1994.

8. Pikul Jr, J. L.; Allmaras, R. R.; Waldman, S. E.; Soil Sci. Soc. Am. J. 1985, 49, 1517.

9. Dermoun, Z.; Belaich, J. P.; Biotechnol. Bioeng. 1985, 27, 1005.

10. McClintock, J. B.; Oecologia 1986, 70, 161.

11. Iversen, E.; Wilhelmsen, E.; Criddle, R. S.; J. Food Sci. 1989, 54, 1246.

12. Nunomura, K.; Ki-Sook, K.; Fujita, T.; J. Gen. Appl. Microbiol. 1986, 32, 361.

13. Hileman, B.; Chem. Eng. News 1992, April 27.

14. Shriver, D. F.; Atkins, P. W.; Langford, C. H.; Inorganic Chemistry, Oxford University Press, Oxford, 1990.

15. Drong, K.; Lamprecht, I.; Pure Appl. Chem. 1993, 65, 1967.

16. Lamprecht, I.; Motzkus, C.; Schaarschmidt, B.; CoenenStass, D.; Thermochim. Acta 1990, 172, 87.

17. Becker, M.; Kraepelin, G.; Lamprecht, I.; Thermochim. Acta 1991, 187, 15.

18. Drong, K.; Lamprecht, I.; Motzkus, C.; Schaarschmidt, B.; Thermochim. Acta 1991, 193, 125.

19. Ljungholm, K.; Norén, B.; Skold, R.; Wadso, I.; Oikos 1979, 33, 15 .

20. Ljungholm, K.; Norén, B.; Wadso, I.; Oikos 1979, 33, 24.

21. Yamano, H.; Takahashi, K.; Agric. Biol. Chem. 1983, 47, 1493.

22. Itoh, S.; Takahashi, K. Agric. Biol. Chem. 1984, 48, 271.

23. Critter, S. A. M.; Simoni, J. A.; Airoldi, C.; Thermochim. Acta 1994, 232, 145.

24. Sposito, G.; The Chemistry of Soils, Oxford University Press: Oxford, 1989.

25. Zelles, L.; Scheunert, I.; Kreutzer, K.; Biol. Fertil. Soils 1987, 3, 381 .

26. Oliveira, J. B.; Menk, J. R. F.; Rotta, C. L.; Levantamento Pedológico Semidetalhado dos Solos do Estado de São Paulo: Supren, Rio de Janeiro, 1979.

27. Rawat, J. P.; Ansari, A. A.; Singh, R. P.; Colloids Surf. 1990, 50, 207.

28. Airoldi, C.; Critter, S. A. M.; Clays Clay Minerals 1997, $45,125$. 
29. Mortensen, U.; Norén, B.; Wadso, I.; Bull. Ecol. Res. Commum. 1973, 17, 189.

30. Barros, N.; Orellana, I. G.; Feijóo, S.; Balsa, R.; Thermochim. Acta 1995, 249, 161.

31. Sparling, G. P. J. Soil Sci. 1983, 34, 381.

32. Critter, S. A. M.; Airoldi, C.; Resultados não publicados.

33. Gustafson, K.; Gustafson, L. J.; Microbiol. Methods 1985 , 4, 103.

34. Pamatmat, M. M.; Science 1982, 215, 395.

35. Pamatmat, M. M.; Graf, G.; Bengtsson, W.; Novak, C. S.; Mar. Ecol. Prog. Ser. 1981, 4, 135.
36. Zelles, L.; Scheunert, I.; Kreutzer, K.; Biol. Fertil. Soils 1987, 4, 211.

37. Kawabata, T.; Yamano, H.; Takahashi, K.; Agric. Biol. Chem. 1983, 47, 1281.

38. Joachimsohn, G. B.; Lamprecht, I. Schaarchmidt, B.; J. Thermal Anal. 1989, 35, 659.

39. Weppen, P.; Thermochim. Acta 1985, 94, 139.

40. Bunker, J. C.; James, A. M.; Microbios 1989, 58, 83.

41. Weppen, P. Thermochim. Acta 1995, 94, 139.

42. Airoldi, C.; Critter, S. A. M.; Thermochim. Acta 1996, $288,73$.

43. Airoldi, C.; Quím. Nova 1994, 17, 175. 